\title{
Evaluation of Antiarthritic Potentials of Methanolic Stem Extract of Tecoma Stans Linn in Wistar Albino Rat
}

\author{
Santhosh $\mathbf{E}^{1^{*}}$, Gangaraju $\mathbf{M}^{2}$, Vivek $\mathrm{KT}^{3}$ \\ ${ }^{1}$ M.pharm, Department of Pharmacology, Gokaraju Rangaraju College of Pharmacy, Osmania \\ University, Hyderabad, India \\ ${ }^{2} \mathrm{HOD}$, Department of Anatomy and Physiology, Gokaraju Rangaraju College of Pharmacy, Osmania \\ University, Hyderabad, India \\ ${ }^{3}$ Professor, Department of Pharmacology, Gokaraju Rangaraju College of Pharmacy, Osmania \\ University, Hyderabad, India
}

Received: December 22, 2017; Accepted: January 05, 2018; Published: March 03, 2018

*Corresponding author: Santhosh E, M.pharm, Department of Pharmacology, Gokaraju Rangaraju College of Pharmacy, Osmania University, Hyderabad, India; Email: santhoshjessy2036@gmail.com

\begin{abstract}
Objective: The present study was designed to investigate the antiarthritic activity of methanolic stem extract of Tecoma stans in wistar albino rats using in vitro albumin denaturation method and in vivo models like complete freunds adjuvant (CFA) induced arthritis and egg albumin induced arthritic models. Acute toxicity studies were carried out and the extract was found to be safe upto $2000 \mathrm{mg} / \mathrm{kg}$ bd.wt.The methanolic stem extract of Tecoma stans significantly lowered protein denaturation. The extract showed significant inhibition of paw volume in both complete freunds adjuvant and egg albumin induced arthritis. Upon treatment with the extract the animals gained weight compared to negative control. The presence of active constituents like alkaloids, glycosides steroids and flavonoids in extract might be responsible for its prominent anti-arthritic activity. From the above it is clear that the methanolic extract of Tecoma stans possess anti-arthritic activity.
\end{abstract}

Key words: Tecoma stans; Antiarthritic activity; Complete freund's adjuvant

\section{Introduction}

Rheumatoid arthritis (RA) is an autoimmune disease in which the body's immune system - which normally protects its health by attacking foreign substances like bacteria and viruses - mistakenly attacks the joints. This creates inflammation that causes the tissue that lines the inside of joints (the synovium) to thicken, resulting in swelling and pain in and around the joints. The synovium makes a fluid that lubricates joints and helps them move smoothly.

If inflammation goes unchecked, it can damage cartilage, the elastic tissue that covers the ends of bones in a joint, as well as the bones themselves. Over time, there is loss of cartilage, and the joint spacing between bones can become smaller. Joints can become loose, unstable, painful and lose their mobility. Joint deformity also can occur. Joint damage cannot be reversed, and because it can occur early, doctors recommend early diagnosis and aggressive treatment to control RA.

Rheumatoid arthritis most commonly affects the joints of the hands, feet, wrists, elbows, knees and ankles. The joint effect is usually symmetrical. That means if one knee or hand if affected, usually the other one is, too. Because RA also can affect body systems, such as the cardiovascular or respiratory systems, it is called a systemic disease. [1]

It affects about $1 \%$ of the population of world in a female and male ratio of 2.5:1. (R1) It caused by number of pro inflammatory molecules released by macrophages including reactive oxygen species and Eicosanoids such as prostaglandins, leukotrienes and cytokines. The regulation of these mediators secreted by macrophages and other immune cells and modulation of Arachidonic acid metabolism by inhibiting enzymes like COX and LOX are the potential target for chronic inflammatory conditions. [2]

Even though various categories like immunosuppressants, NSAIDs, steroidal anti-inflammatory drugs are being used till now, the potential side effects give a limitation for their use. Now it is a growing concern allover for the development of new safe, potent, less toxic Antiarthritic drug. Hence, there is a need to explore for more naturally available alternatives, so that their therapeutic values can be assessed and expanded. [3]

Plants are one of the most important sources of medicines. The use of natural remedies for the treatment of inflammatory and painful conditions has a long history, starting with Ayurvedic treatment, and extending to the European and other systems of traditional medicines. Plant drugs are known to play a vital role in management of inflammatory diseases. [4] 
Tecoma stans Linn belonging to family Bignoniaceae commonly known as Yellow bells in India. The plant has been reported to have anti-inflammatory, antibacterial, antidiabetic, antispasmodic, anti-nociceptive, nephroprotective and anticancer properties. Tecoma stans plant have traditional claim for use in arthritic disorder. But no pharmacological work has been done on evaluation of its Antiarthritic activity. So the present study was carried out to evaluate Antiarthritic effect of methanolic stem extract of Tecoma stans in wistar albino rats. [5]

\section{Materials and Methods}

\section{Collection and Authentication of Plant Material}

The stem of Tecoma stans were collected from Warangal in the month of December 2016, this plant material was identified and authenticated by pharmacognist. They were dried under shade and pulverized in the laboratory.

\section{Preparation of Extract}

The stem powder of Tecoma stans was dried. Then the powder $(250 \mathrm{~g})$ was successively extracted using methanol $(1000 \mathrm{ml})$ in a soxhlet extraction apparatus. It is a continuous extraction in which the same solvent can be circulated through the extractor for several times. This process involves extraction followed by evaporation of the solvent. The vapors of solvent are taken to condenser and condensed liquid is returned to the drug for continuous extraction. The dried Tecoma stans extract was dissolved in distilled water and used for the present study. [6]

\section{Phytochemical Screening of the Extract}

The extract of Tecoma stans was subjected to Preliminary phytochemical screening for the presence of phytoconstituents like alkaloids, glycosides, phenols, tannins, flavonoids, saponin, steroids. Results are tabulated.

\section{Experimental Animals}

Wistar strain of albino rats (200-250 g) of either sex were used for this carrageenan experiment. The animals were housed in standard metal cages and provided with food and water ad libitum. Six animals were used in each experiment

\section{Acute Toxicity Studies}

Studies were carried out in order to check the toxic effects of extract. The study was performed as per Organization for Economic Cooperation and Development (OECD) guideline no. 425 .

Healthy adult Swiss mice (20-30 gm) were subjected to acute oral toxicity studies as per Organization for Economic Cooperation and Development (OECD) guidelines. Animals were observed individually after dosing at least once during the first $30 \mathrm{~min}$, periodically during the first $24 \mathrm{~h}$, with special attention given during the first $4 \mathrm{~h}$, and daily thereafter, for a total of 14 days. The changes in skin, fur, eyes, mucous membranes, respiratory, circulatory, autonomic, central nervous system, somatomotor activity and behaviour pattern were noted.

\section{In-Vitro Anti-Arthritic Activity}

\section{Inhibition of Albumin Denaturation Method}

0.2 mL offresh hen's egg albumin, $2.8 \mathrm{~mL}$ of phosphate buffered saline (pH 6.4) and test solution of different concentrations $(2,5$, $10,20,30$ and $60 \mu \mathrm{g} / \mathrm{mL}$ ) or standard drug diclofenac sodium $(0.05 \mathrm{~mL})$ of different concentrations $(2,5,10,20,30$ and 60 $\mu \mathrm{g} / \mathrm{mL}$ ) were mixed to form a reaction mixture of $5 \mathrm{~mL}$ Double distilled water of same volume served as control. The samples were incubated at $37 \pm 2^{\circ} \mathrm{C}$ in a BOD incubator for $15 \mathrm{~min}$ followed by heating at $70{ }^{\circ} \mathrm{C}$ for $5 \mathrm{~min}$. UV-Visible spectrophotometer was used to measure the absorbance at $660 \mathrm{~nm}$. Five doses of the test and one dose of the reference drug $(400 \mu \mathrm{g} / \mathrm{mL})$ were assayed and distilled water used as control. [7]

The percentage inhibition of protein denaturation was calculated by the following formula:

Percentage inhibition $=100 \times 1$ - [absorbance of test sample/ absorbance of control]

\section{In Vivo Anti-Arthritic Activity}

\section{Egg albumin induced arthritis}

The rats were selected randomly for the study and were sub divided into following groups [Table 1].

\begin{tabular}{|c|c|}
\hline \multicolumn{2}{|c|}{$\begin{array}{c}\text { Table 1: Experimental animal groups for Egg albumin induced } \\
\text { arthritis }\end{array}$} \\
\hline Groups & Treatment \\
\hline I & Rats received normal saline (s.c) \\
\hline II & Rats received $0.1 \mathrm{~mL}$ of egg albumin (s.c) \\
\hline III & $\begin{array}{r}\text { Rats received METS }(200 \mathrm{mg} / \mathrm{kg} \text { bd. wt, p.o) }+0.1 \\
\mathrm{mL} \text { of Egg albumin (s.c) }\end{array}$ \\
\hline IV & $\begin{array}{r}\text { Rats received METS }(400 \mathrm{mg} / \mathrm{kg} \text { bd. wt, p.o) }+0.1 \\
\mathrm{mL} \text { of Egg albumin (s.c) }\end{array}$ \\
\hline V & $\begin{array}{r}\text { Rats received diclofenac sodium }(15 \mathrm{mg} / \mathrm{kg} \text { bd. } \mathrm{wt}, \\
\text { p.o) }+0.1 \mathrm{~mL} \text { of Egg albumin (s.c) }\end{array}$ \\
\hline
\end{tabular}

Animals were divided into five groups of six animals each. Group I served as control received normal saline, Group II served as disease control received only egg albumin. Group III and IV received the test extract. Group V received diclofenac sodium (15 $\mathrm{mg} / \mathrm{kg}$ bd.wt.The. i.p.) served as standard.

The in vivo anti-arthritic study was evaluated using egg albumin induced edema (Phlogistic agent) model. $0.1 \mathrm{~mL}$ of egg albumin from fresh egg was subcutaneously injected into the right hind paw of the rats. The rats were administered the test sample and reference drug 30 minutes before inducing inflammation. The rat paw volume was measured at intervals of $0 \mathrm{~min}, 30 \mathrm{~min}$, $60 \mathrm{~min}, 90 \mathrm{~min}, 120 \mathrm{~min}, 150 \mathrm{~min}, 180 \mathrm{~min}$ and $24 \mathrm{hrs}$.

The \% inhibition of the edema was determined by the following equation;

\% Inhibition = Io - Ii / Io X 100 
where;

Io = change in paw volume in control group;

Ii = change in paw volume in treated group

\section{Complete Freund's adjuvant (CFA) Induced Arthritis}

The rats were selected randomly for the study and were subdivided into following groups. [Table 2]

Table 2: Experimental animal groups for Complete Freund's Adjuvant (CFA) induced arthritis

\begin{tabular}{|c|c|}
\hline Groups & Treatment \\
\hline I & Rats received normal saline (p.o) \\
\hline II & Rats received 0.1 mL of Complete Freund's adjuvant (s.p) \\
\hline III & $\begin{array}{r}\text { Rats received } 0.1 \mathrm{~mL} \text { of Complete Freund's adjuvant (s.p) + } \\
\text { METS }(200 \mathrm{mg} / \mathrm{kg} \text { bd. wt (p.o), 8-21 days) }\end{array}$ \\
\hline IV & $\begin{array}{r}\text { Rats received } 0.1 \mathrm{~mL} \mathrm{of} \mathrm{Complete} \mathrm{Freund's} \mathrm{adjuvant} \mathrm{(s.p)} \mathrm{+} \\
\text { METS (400 mg/kg bd. wt (p.o), 8-21 days) }\end{array}$ \\
\hline V & $\begin{array}{r}\text { Rats received 0.1 } \mathrm{mL} \mathrm{of} \mathrm{Complete} \mathrm{Freund's} \mathrm{adjuvant} \mathrm{(s.p)} \mathrm{+} \\
\text { diclofenac sodium (15 mg/kg bd. wt (p.o), 8-21 days) }\end{array}$ \\
\hline
\end{tabular}

\section{Procedure}

Animals were divided into five groups of six animals each Group I served as control received normal saline, Group II served as disease control received only CFA. Group III and IV received the different doses of test extract. Group V received diclofenac sodium (15 mg/kg bd.wt, i.p.) served as standard.

Rat adjuvant arthritis is widely used for evaluation of various anti-arthritic agents. The hallmarks of this model are reliable onset and progression of robust easily measurable, periarticular inflammation, marked bone resorption and periosteal bone proliferation. In this model wistar albino rats (150-200, grams 6/group) are generally used in studies of adjuvant arthritis. Induction of adjuvant arthritis is done with Complete Freund's Adjuvant (CFA).

Rats were injected, subcutaneously, $0.1 \mathrm{~mL}$ of complete Freund's adjuvant into the plantar region of the left hind paw. The changes in the paw volume (left and right) were measured on various days up to 21 days. The herbal product at $(200,400$ $\mathrm{mg} / \mathrm{kg} /$ day $)$ and diclofenac sodium at $(15 \mathrm{mg} / \mathrm{kg})$ doses were administered orally for 14 days after 7 days of Freund's adjuvant administration.

On the $21^{\text {st }}$ day rats were sacrificed by cervical dislocation and ankle joints were isolated from the injected hind paw. [8]

\section{Statistical Analysis}

The values were expressed as mean \pm SEM $(n=6)$. The statistical significance was assessed using student t-test or oneway analysis of variance (ANOVA) followed by Dunnett's test and $\mathrm{P}<0.05, \mathrm{P}<0.01$ were considered to be statistically significant.

\section{Results and Discussion}

\section{\% Yield of the Extract}

The methanolic stem extract of Tecomastans was prepared by soxhlet extraction technique; $250 \mathrm{~g}$ of powdered stem was extracted using $1000 \mathrm{ml}$ of methanol.

The percentage yield of the extract was found to be.

$\%$ yield of extract $=$ Amount of extract obtained $/$ Amount of powder used $\times 100$

$$
\begin{aligned}
& =15 \mathrm{~g} / 250 \mathrm{~g} \times 100 \\
& =6 \% \mathrm{w} / \mathrm{w}
\end{aligned}
$$

\section{Preliminary Phytochemical Analysis of Tecoma stans}

Phytochemical screening of the methanolic stem extract revealed the presence of glycosides, saponins, flavonoids, phytosterols, alkaloids, carbohydrates, fats, phenolic compounds, amino acids and tannins. [Table 3]

\begin{tabular}{|c|c|}
\hline \multicolumn{2}{|l|}{ Table 3: Preliminary phytochemical analysis } \\
\hline Phytochemical constituents & Inference \\
\hline Alkaloids & ++ \\
\hline Glycosides & ++ \\
\hline Saponins & ++ \\
\hline Steroids & ++ \\
\hline Flavonoids & ++ \\
\hline Phenols & + \\
\hline Tannins & + \\
\hline Fats & - \\
\hline Proteins and amino acids & + \\
\hline Note: + indicates Present; - indicates Absent \\
\hline
\end{tabular}

\section{Inhibition of Albumin Denaturation}

Protein Denaturation is a process in which proteins lose their complex structure by application of external stress, there by lose their biological function when denatured. Denaturation of proteins is a well documented cause of inflammation. METS significantly inhibited heat induced albumin denaturation. METS at concentrations of $100,200,300,400 \mu \mathrm{g} / \mathrm{ml}$ showed $56.10,70.20$, $78.10,85.60 \%$ inhibition of protein denaturation respectively. Diclofenac sodium, a standard anti- inflammatory drug showed the maximum inhibition of $95.20 \%$ at the concentration of $400 \mu \mathrm{g} / \mathrm{ml}$ compared with control. [Table 4][Figure 1]

The Antiarthritic activity of the extract was further confirmed by using albumin denaturation method. Standard diclofenac sodium at a dose of $400 \mathrm{mg} / \mathrm{mL}$ produced prominent $\%$ stabilization (95.20\%). The methanolic extract of the plant showed marked increase in the \% stabilization. The activity of $400 \mathrm{mg} / \mathrm{mL}$ of extract (85.60\%) was found to be better than that of $100 \mathrm{mg} / \mathrm{kg}(56.10 \%)$. The activity of the $400 \mathrm{mg} / \mathrm{mL}$ of the extract was comparable to that of standard. 


\begin{tabular}{|c|c|c|c|c|}
\hline S. No & Treatment & $\begin{array}{c}\text { Concentration } \\
(\mu \mathrm{g} / \mathrm{mL})\end{array}$ & $\begin{array}{c}\text { Absorbance } \\
(660 \mathrm{~nm})\end{array}$ & $\begin{array}{c}\% \\
\text { Inhibition }\end{array}$ \\
\hline 1 & Saline & - & 4.1 & - \\
\hline 2 & METS & 100 & 1.8 & 56.1 \\
\hline 3 & METS & 200 & 1.2 & 70.2 \\
\hline 4 & METS & 300 & 0.9 & 78.1 \\
\hline 5 & METS & 400 & 0.6 & 85.6 \\
\hline 6 & $\begin{array}{l}\text { Diclofenac } \\
\text { sodium }\end{array}$ & 400 & 0.2 & 95.2 \\
\hline
\end{tabular}

\section{Egg Albumin Induced Arthritis}

[Table 5]Values were expressed as mean \pm SEM $(n=6)$. Statistical analysis was performed by using ANOVA followed by Dunnet's t test by comparing with normal control, disease control

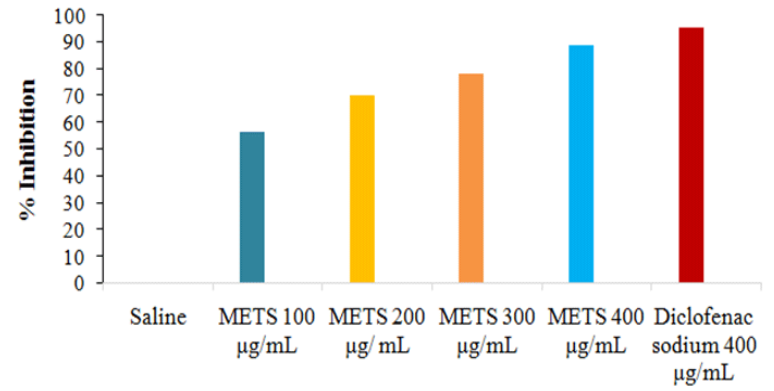

Treatment

Figure 1:Effect of methanolic stem extract of Tecoma stans by using albumin denaturation method.

and standard. Significant values were expressed as control group $(\mathrm{a}=\mathrm{p}<0.01, \mathrm{~b}=\mathrm{p}<0.05)$, disease control $\left({ }^{* *} \mathrm{p}<0.01,{ }^{*} \mathrm{p}<0.05\right)$ and standard $(A=p<0.01, B=p<0.05)$.

Table 5: Antiarthritic activity of methanolic extract of Tecomastans by using egg albumin induced method

\begin{tabular}{|c|c|c|c|c|c|c|c|c|}
\hline \multirow{3}{*}{ Groups } & \multirow{3}{*}{ Treatment } & \multicolumn{7}{|c|}{ Mean paw volume $(\mathrm{mL})$} \\
\hline & & \multicolumn{7}{|c|}{ Time in minutes } \\
\hline & & $\mathbf{0}$ & 30 & 60 & 90 & 120 & 180 & 1440 \\
\hline $\mathbf{I}$ & Saline & $0.22 \pm 0.04$ & $0.22 \pm 0.03$ & $0.23 \pm 0.04$ & $0.24 \pm 0.02$ & $0.24 \pm 0.05$ & $0.24 \pm 0.08$ & $0.24 \pm 0.03$ \\
\hline II & $\begin{array}{l}0.1 \mathrm{~mL} \text { egg } \\
\text { albumin }\end{array}$ & $0.23 \pm 0.03$ & $0.66 \pm 0.05 \mathrm{a}$ & $0.74 \pm 0.02 \mathrm{a}$ & $0.85 \pm 0.04 \mathrm{a}$ & $0.89 \pm 0.04 \mathrm{a}$ & $0.92 \pm 0.06 \mathrm{a}$ & $0.93 \pm 0.04 \mathrm{a}$ \\
\hline III & $\begin{array}{l}\text { METS } 200 \mathrm{mg} / \\
\mathrm{kg}+0.1 \mathrm{~mL} \text { egg } \\
\text { albumin }\end{array}$ & $0.22 \pm 0.02$ & $0.54 \pm 0.03^{*}, \mathrm{a}$ & $0.52 \pm 0.03^{* *}, \mathrm{~B}$ & $0.50 \pm 0.09^{* *}, \mathrm{~A}$ & $0.50 \pm 0.02^{* *}, \mathrm{~A}$ & $0.48 \pm 0.02^{* *}, \mathrm{~A}$ & $0.48 \pm 0.04^{*}, \mathrm{~A}$ \\
\hline IV & $\begin{array}{l}\text { METS } 400 \mathrm{mg} / \\
\mathrm{kg}+0.1 \mathrm{~mL} \text { egg } \\
\text { albumin }\end{array}$ & $0.24 \pm 0.04$ & $0.50 \pm 0.02 *, \mathrm{~B}$ & $0.46 \pm 0.03^{* *}, \mathrm{~B}$ & $0.42 \pm 0.02 * *, \mathrm{~B}$ & $0.39 \pm 0.03^{* *}, \mathrm{a}$ & $0.38 \pm 0.06^{* *}, \mathrm{a}$ & $0.36 \pm 0.09^{* *}, \mathrm{~B}$ \\
\hline $\mathbf{v}$ & $\begin{array}{l}\text { Diclofenac sodium } \\
(15 \mathrm{mg} / \mathrm{kg})+0.1 \\
\text { mL egg albumin }\end{array}$ & $0.21 \pm 0.03$ & $0.46 \pm 0.03^{* *}, \mathrm{~b}$ & $0.43 \pm 0.02^{* *}, \mathrm{~b}$ & $0.40 \pm 0.04^{* *}, \mathrm{~b}$ & $0.36 \pm 0.05^{* *}, \mathrm{~b}$ & $0.34 \pm 0.03^{* *}, \mathrm{~b}$ & $0.31 \pm 0.05^{* *}, \mathrm{~b}$ \\
\hline
\end{tabular}

[Figure 2]The Antiarthritic activity of the extract was further confirmed by using egg albumin induced model. Standard diclofenac sodium at a dose of $15 \mathrm{mg} / \mathrm{kg}$ had shown significant inhibition of paw volume $(0.31 \pm 0.05)$ compared to disease control group $(0.93 \pm 0.04)$. The methanolic extract of the plant showed significant inhibition of paw volume. The inhibitory activity of $400 \mathrm{mg} / \mathrm{kg}$ bd.wt. of extract $(0.36 \pm 0.09)$ was found to be better than that of $200 \mathrm{mg} / \mathrm{kg}$ bd.wt. $(0.48 \pm 0.04)$. The activity of the $400 \mathrm{mg} / \mathrm{kg}$ bd.wt. of the extract was comparable to that of standard.

\section{Complete Freund's adjuvant (CFA) Induced Arthritis}

[Table 6]Values were expressed as mean \pm SEM $(n=6)$. Statistical analysis was performed by using ANOVA followed by Dunnett's t test by comparing with normal control, disease

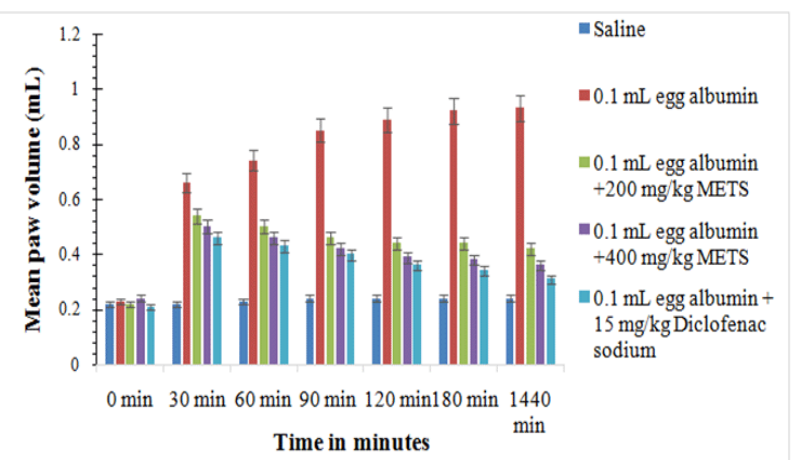

Figure 2:Effect of methanolic stem extract of Tecoma stans by using egg albumin induced model 


\begin{tabular}{|c|c|c|c|c|c|c|}
\hline \multirow{2}{*}{ Table 6: Antiarthritic activity of methanolic extract of Tecomastans by using CFA method } \\
\hline \multirow{2}{*}{ Groups } & Treatment & Dose (mg/kg) & \multicolumn{4}{|c|}{ Mean paw volume (mL) } \\
\cline { 4 - 7 } & & 0th Day & 7th Day & 14th Day & 21st Day \\
\hline I & Normal control & Saline & $0.20 \pm 0.04$ & $0.20 \pm 0.06$ & $0.20 \pm 0.01$ & $0.22 \pm 0.08$ \\
\hline II & CFA & $0.1 \mathrm{~mL}$ & $0.25 \pm 0.02$ & $0.75 \pm 0.02 \mathrm{a}$ & $0.94 \pm 0.01 \mathrm{a}$ & $0.92 \pm 0.09 \mathrm{a}$ \\
\hline III & CFA +METS & $0.1 \mathrm{~mL}+200 \mathrm{mg} / \mathrm{kg}$ & $0.30 \pm 0.04$ & $0.68 \pm 0.02,{ }^{*}, \mathrm{a}, \mathrm{A}$ & $0.63 \pm 0.02^{* *}, \mathrm{a}$ & $0.60 \pm 0.10^{*}, \mathrm{a}$ \\
\hline IV & CFA +METS & $0.1 \mathrm{~mL}+400 \mathrm{mg} / \mathrm{kg}$ & $0.30 \pm 0.02$ & $0.60 \pm 0.04^{*}, \mathrm{a}$ & $0.50 \pm 0.03^{* *}, \mathrm{~B}$ & $0.46 \pm 0.02^{* *}, \mathrm{~B}$ \\
\hline & CFA +Diclofenac & $0.1 \mathrm{~mL}+15 \mathrm{mg} / \mathrm{kg}$ & $0.25 \pm 0.05$ & $0.55 \pm 0.02^{* *}$ & $0.46 \pm 0.01^{* *}, \mathrm{~b}$ & $0.40 \pm 0.02^{* *}, \mathrm{~b}$ \\
\hline
\end{tabular}

control and standard. Significant values were expressed as control group $(a=p<0.01, b=p<0.05)$, disease control $(* * p<0.01$, $\left.{ }^{*} \mathrm{p}<0.05\right)$ and standard $(\mathrm{A}=\mathrm{p}<0.01, \mathrm{~B}=\mathrm{p}<0.05)$.

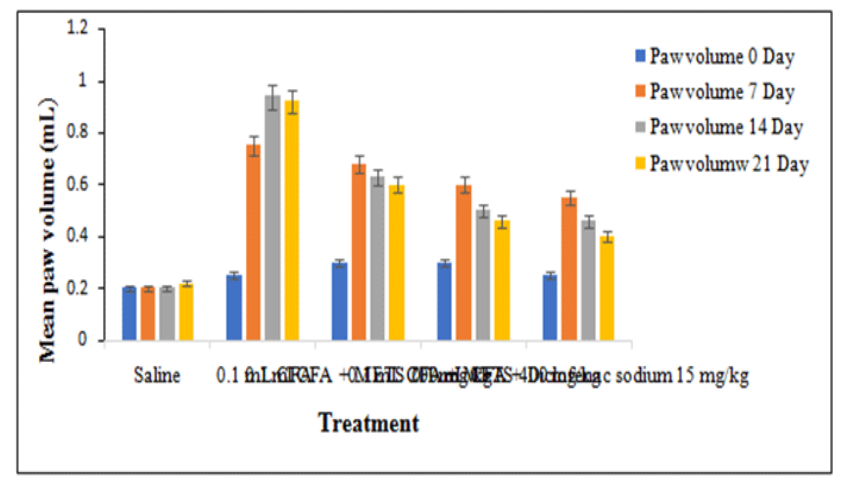

Figure 3:Effect of methanolic stem extract of Tecomastans by using Complete Freunds adjuvant induced model

[Figure 3]The Antiarthritic activity of the extract was carried out by Complete Freunds adjuvant induced arthritis. Standard diclofenac sodium at a dose of $15 \mathrm{mg} / \mathrm{kg}$ had shown significant inhibition of paw volume $(0.40 \pm 0.02)$ compared to disease control group $(0.92 \pm 0.09)$. The methanolic extract of the plant showed significant inhibition of paw volume. The inhibitory activity of $400 \mathrm{mg} / \mathrm{kg}$ bd.wt. of extract $(0.46 \pm 0.02)$ was found to be better than that of $200 \mathrm{mg} / \mathrm{kg}$ bd.wt. $(0.60 \pm 0.10)$. The activity of the $400 \mathrm{mg} / \mathrm{kg} \mathrm{bd}$.wt. of the extract was comparable to that of standard.

\section{Discussion}

Phytochemical screening of methanolic stem extract of Tecomastans showed the presence of different phytoconstituents like glycosides, saponins, flavonoids, phytosterols, alkaloids, carbohydrates, phenols, amino acids and tannins. Earlier studies also reported that phytoconstituents like saponins, flavonoids, alkaloids, phenols and phytosterols are known to possess antiarthritic properties. [9]

Rheumatoid arthritis, an autoimmune disease, involves denaturation of proteins and hence production of auto-antigens. Invitro Antiarthritic activity of the methanolic extract was carried out by the protein denaturation method.

Denaturation of protein is one of the causes of rheumatoid arthritis. Production of autoantigens in certain rheumatic diseases may be due to in vivo denaturation probably involves alteration in electrostatic, hydrogen, hydrophobic and disulphide bonding. Several anti-inflammatory drugs have shown dose dependent ability to inhibit internally induced protein denaturation. In our present study, METS (Methanolic stem extract of Tecomastans) inhibited heat induced protein denaturation and may be one of the reason of possessing anti-arthritic activity. Inflammation is the tissue response to injury and involves a complex process of enzymatic reactions. [10]

In the present study, the Antiarthritic activity of METS was evaluated by using two in vivo experimental models of arthritis, viz. Egg albumin and Complete Freund's Adjuvant induced arthritis. Egg albumin induced model is an acute method of screening of anti-arthritic potential. It involves tissue mediated response and localized inflammation is produced by Egg albumin injection into the rat paw. In the present study the methanolic extract of Tecoma stans at doses 200 and $400 \mathrm{mg} / \mathrm{kg}$ bd.wt significantly inhibited the paw edema induced by Egg albumin. The effect may be due to certain changes in inflammatory response which are comparable with Diclofenac sodium. Thus, to further confirm the activity of the extract, its efficacy in reducing joint inflammation in CFA induced arthritis in rats was evaluated.

CFA - induced arthritis is a chronic model used to study the pathogenesis of rheumatoid arthritis for testing therapeutics. One of the reasons for the wide utilization of this model is a strong correlation between the efficacy of therapeutic agents in this model and in rheumatoid arthritis in humans, and this model is characterized by swelling in joints with the influence of inflammatory cells, erosion of joint cartilage and bone destruction and remodeling.

Also, soft tissue swelling around the ankle joints was appeared during the progress of arthritis in CFA injected rats, which was considered as oedema of the exacting tissues. Bacterial peptidoglycan and muramyl dipeptide are responsible for the induction of adjuvant arthritis. Determination of paw oedema is according to the grapevine simple, susceptible and rapid procedure to evaluate the degree of inflammation and assess the therapeutic effects of drugs.

CFA induced significant inflammation of the ankle joint of the rats. METS at doses 200 and $400 \mathrm{mg} / \mathrm{kg}$ bd.wt significantly inhibited paw swelling in arthritic rats. The inhibition of 
inflammation by the extract might be due to inhibition of bacterial peptidoglycan and muramyl dipeptide which are responsible for the swelling, bone and cartilage erosion. There was significant inhibition of weight loss in the extract treated group and it was comparable to standard diclofenac. This inhibition might be due to prevention of production of cytokine such as TNF- $\alpha$ and interleukin-1B by the phytoconstituents present in the extract. [11-15]

\section{Conclusion}

The results obtained in this present study indicate that Tecoma stans not only directs towards the control of arthritis progression and / or the inflammation associated with joint synovitis, but also prevents cartilage and bone destruction of arthritic joints. Hence orally applicable Tecoma stans, may have great potential as an alternative to the therapeutic agents currently available for treatment of RA.

\section{Acknowledgement}

The authors are thankful to management of Gokaraju Rangaraju College of Pharmacy for their timely support.

\section{References}

1. Scott DL, Wolfe F, Huizinga TW. Rheumatoid arthritis. Lancet. 2010; 376(9746):1094-1108. Doi: 10.1016/S0140-6736(10)60826-4.

2. Tripathi KD. Essentials of Medical Pharmacology. 2010; 7th Edition. Jaypee Publications.

3. Kore K, Shete R. Anti arthritic activity of hydro alcoholic extract of Lawsonia Innermis'. International Journal of Drug Development and Research. 2010;3(4): 217-224.

4. Margaret AN, Scott KD. Scientific evaluation of traditional Chinese medicine. Journal of Alternate Complementary Medicine. 2007; 5(2):181-189; Doi: 10.1089/acm.1999.5.177
5. Archana S, Nagori P. Tecomastansan important medicinal plant. International Journal of Pharmaceutical Education. 2013; 3(2):13-20.

6. Suchita M, Praveen K. In vivo Anti inflammatory and anti arthritic activity of ethanolic extract of Asparagus Racemosus roots. International Research Journal of Pharmacy. 2013; 4(4): 167-172.

7. Sreekumari N, Yasmin M. Anti arthritic property of Rhizoporamucuronata by Protein and albumin denaturation assay. International Journal of Pharma Sciences and Research. 2015; 6(1: 4824-4885.

8. Manjusha C, Vipin K, Surender S. Anti-arthritic activity of Barleriaprionitis Linn. Leave in acute and chronic models. Bulletin of Faculty of Pharmacy. 2014; 52: 199-209.

9. Anburaj G, Manikandan R. Preliminary phytochemical screening of extract of Tecomastans. International Journal of Engineering Research. 2016; 1(1): 50-53.

10. Sheelarani.T, Gopal,Seethalakshmi.S and Chitra.K. 'In vitro antiarthritic and anti-inflammatory activity in aerial parts of Myxopyrum SerratulumA. W Hill. International Journal of Pharmaceutical Sciences Review and Research. 2014; 28(2): 162-163.

11. Rajaram, Ravindra reddy. Evaluation of anti arthritic activity of caesalpinia pulcherrima in adjuvant arthritic rat model induced by complete freund's adjuvant. Journal of Young Pharmacists; 2015; 7(2: 128-132; Doi: 10.5530/jyp.2015.2.12

12. Sunitha Verma. Phytochemical and pharmacological review study on Tecoma stans Linn, Journal of Medicinal Plant Studies. 2016; 4(5):162164.

13. Kokate CK. Practical pharmacognosy. New delhi: Vallabh prakashan; 1994; 107

14. Shravan Kumar, Kishore G. In-vitro anti arthritic activity of leaves of Physalis angulate. International Journal of Pharma and Research. $2011 ; 1(3)$ 